\title{
The relevance of social contexts and social action in reducing substance use and victimization among women participating in an HIV prevention intervention in Cape Town, South Africa
}

\author{
This article was published in the following Dove Press journal: \\ Substance Abuse and Rehabilitation \\ 27 June 2013 \\ Number of times this article has been viewed
}

\author{
Elizabeth Reed' \\ Andrea $\mathrm{N}$ Emanuel $^{2}$ \\ Bronwyn Myers ${ }^{3,4}$ \\ Kim Johnson ${ }^{3}$ \\ Wendee MWechsberg ${ }^{2,5-7}$ \\ 'George Washington University \\ School of Public Health, Department \\ of Prevention and Community \\ Health, Washington, DC, USA; ${ }^{2}$ RTI \\ International, Research Triangle Park, \\ NC, USA; ${ }^{3}$ Alcohol and Drug Abuse \\ Research Unit, Medical Research \\ Council, Cape Town, South Africa; \\ ${ }^{4}$ Department of Psychiatry and Mental \\ Health, University of Cape Town, Cape \\ Town, South Africa; ${ }^{5}$ Gillings Global \\ School of Public Health, University of \\ North Carolina, Chapel Hill, NC, USA; \\ ${ }^{6}$ Psychology in the Public Interest, \\ North Carolina State University, \\ NC, USA; ${ }^{7}$ Psychiatry and Behavioral \\ Sciences, Duke University School of \\ Medicine, NC, USA
}

Objectives: To examine qualitatively how women's social context and community mobilization (eg, mobilizing women to take social action and engaging their community in social change) influence substance use abstinence and victimization among women participating in a human immunodeficiency virus (HIV) intervention in Cape Town, South Africa.

Methods: Thirty women who had participated in a randomized controlled trial of a groupdelivered intervention to address substance use, gender-based violence, and associated risk for HIV (The Women's Health CoOp) were selected to participate in semi-structured interviews about their perceived impact of the intervention on their substance use and exposure to victimization. The Women's CoOp intervention involved creating a new positive social environment for women within a group setting that also fostered women's social action (eg, educating peers or family members) in the community. Interviews were analyzed using content analysis and coded to examine women's descriptions of social contexts and social action, and the influence of these on women's substance use abstinence and exposure to victimization.

Results: Social support (eg, via program staff and other participants) and social action (eg, engaging others in the community on issues relevant to substance use prevention or other health topics) promoted within the program, as well as outside social influences within women's life contexts (eg, support from non-substance using family or male partners, leaving male partners or other peer relationships characterized by drug use, or finding employment) were key factors reported by women in terms of facilitating their substance use abstinence and in reducing women's exposures to victimization.

Conclusion: Findings highlight the potential for group-delivered interventions that include mobilizing women to take social action in the larger community to be effective approaches for facilitating substance use abstinence, reductions in victimization, and ultimately, to address the intersection between substance use, violence, and HIV risk among women in this high HIV prevalence setting.

Keywords: HIV prevention, substance use, social context, women

\section{Introduction}

Human immunodeficiency virus/acquired immune deficiency syndrome (HIV/AIDS) is currently the leading cause of premature death for all nine provinces in the Republic of South Africa. ${ }^{1}$ In 2010, an estimated $17.9 \%$ of the general population between 15 and 49 years of age were HIV positive and HIV incidence was estimated at 1.47 per 100 person years, translating into more than 330,000 new infections per year. ${ }^{2}$ South African women are disproportionately affected by HIV, which is predominantly
Correspondence: Wendee M Wechsberg RTI International, 3040 East Cornwallis Road, Research Triangle Park, NC 27709-2194, USA

$\mathrm{Tel}+\mid$ 91954| 6422

$\mathrm{Fax}+19194855555$

Emailwmw@rti.org 
heterosexually transmitted in the country. ${ }^{3}$ Two factors that intersect with sexual risk taking behaviors to heighten South African women's vulnerability to HIV are exposure to gender-based violence and substance use; both of which are highly prevalent in the country.-9

While HIV prevalence in the Western Cape Province is significantly lower than the national estimate, this province is one of the few where the prevalence of HIV appears to be increasing. ${ }^{2}$ It is also a province that has been greatly affected by substance use. Findings from a nationally representative survey indicate that relative to the other provinces, the Western Cape province has the highest lifetime prevalence of substance use disorders which exceed $20 \%$ of the general population. ${ }^{10}$ In addition, this province has the highest prevalence of methamphetamine use ${ }^{11}$ and alcohol use ${ }^{12}$ in the country. These high rates of substance use increase vulnerability to HIV among women, given the association of substance use with various sexual risk behaviors including non-condom use and trading sex in exchange for substances or money to buy substances. ${ }^{6,13-15}$

The context of gender inequality and gender-based violence also places South African women at increased risk for HIV infection. Gender-based violence is commonplace in South Africa, with studies reporting that between one in four and one in two South African women have lifetime histories of violence exposure. ${ }^{4,16,17}$ This is cause for concern as genderbased violence from male partners (particularly sexual violence and coercion, rape, and refusal to use condoms) has been identified as a primary factor in increasing HIV risk among women in South Africa. ${ }^{16,18,19}$ Women's fear of victimization undermines their ability to control the circumstances of sex and negotiate safer sex practices, such as condom use ${ }^{18,20}$ and controlling male partners may insist on unprotected sex. ${ }^{18}$ Furthermore, abusive males who perpetrate physical and/or sexual violence against women are more likely to have HIV and report greater HIV risk behaviors. ${ }^{21-23}$

This evidence of the juncture between substance use, gender-based violence, and sexual risk behaviors highlights the need for preventative interventions that address these intersecting risks for HIV among vulnerable women in the Western Cape. Recently there have been some studies targeting these related risks for HIV among women in this province. For instance, a pilot study explored the relative effectiveness of a group-delivered versus an individual-delivered womanfocused intervention for reducing substance use, gender-based violence, and associated HIV risk among poor, substance-using women. ${ }^{23}$ The study findings suggest that women in both the individual and group interventions reduced their substance use, sex risk behavior, and victimization. Additionally, the group intervention created an ongoing effect in the community. Specifically, women who were randomized to the group format continued to meet and engage others in the community after the study ended to provide support for one another and reinforce positive changes. $^{23}$

Increasingly, studies have documented the utility of community mobilization towards social action (eg, creating groups or collectives to promote positive social support networks and to take action in engaging the community on important social issues to improve conditions fostering health and wellbeing) as an effective strategy in sexual risk reduction programs to prevent HIV among highly impacted populations of women in multiple global contexts. ${ }^{24-30}$ These evaluation studies have been conducted among other vulnerable groups of women, including women in high HIVprevalence rural communities of South Africa, as well as multiple studies among female sex workers; these previous efforts have involved mobilizing women to address high rates of gender-based violence and other conditions promoting HIV risk among women. ${ }^{24-30}$ Yet, there has been a paucity of work evaluating the utility of social action strategies among substance using populations of women at high risk for HIV, regarding the influence of these approaches on substance use, victimization, and associated HIV risks. While some previous substance use reduction programs have used interventions delivered in group formats, ${ }^{31,32}$ few studies have employed social action strategies as part of these interventions and no studies, to our knowledge, have evaluated the impact of such social action strategies on substance use.

The purpose of the present study is to address this gap through examining women's responses via in-depth interviews to an HIV risk reduction intervention targeting substance-using women from poor communities in the Western Cape. The current paper aims to expand on findings from the evaluation of this intervention which documented significant reductions in substance use, particularly for the group-delivered intervention. ${ }^{33}$ Building on these previous findings, this paper aims to explore qualitatively how social context and social action, specifically, related to women's involvement in group-delivered interventions and women's exposures within their social contexts outside of the program, influenced their abstinence from substance use and exposure to victimization.

\section{Methods}

\section{Recruitment, eligibility criteria, and intervention description}

This study was conducted among women participating in an HIV prevention study within urban and disadvantaged 
communities surrounding the Cape Town International Airport. Recruitment for the HIV prevention intervention study involved street outreach in the targeted township communities of interest, passing out fliers, and approaching adults to describe the study and ask permission to screen for study eligibility. A rigorous sampling plan was developed to ensure a balanced recruitment of women across all disadvantaged communities in this area of Cape Town. To be eligible, participants had to be female; use at least one drug other than alcohol on at least 13 of the past 90 days; be sexually active in the past 90 days; be between 18 and 35 years of age; provide written consent to participate, including consent for HIV testing; and be able to provide verifiable locator information. A more detailed description of the methods for recruitment in the HIV prevention study has been outlined in our previously published works. ${ }^{33-35}$

Eligible women for the HIV prevention study were randomized into one of three study conditions: a womenfocused group (Women's Health CoOp) that included HIV counseling and testing (HCT) and addressed substance use, violence, sexual risk, and gender inequality; an equal attention comparison group (nutrition intervention) that provided nutritional education and HCT; or HCT only. The study design and more detailed information regarding the intervention and control/comparison arms are described in a previously published work. ${ }^{33}$ The Women's Health CoOp intervention was delivered over two sessions, with each lasting approximately 120 minutes. ${ }^{33}$ Session 1 provided information about HIV risks associated with substance use and taught sexual and condom negotiation skills. Session 2 focused on relationship power, building communication and negotiation skills with male partners, and strategies for avoiding potentially violent situations. The process of developing and adapting this intervention for this population has been described in detail elsewhere. ${ }^{14,33,36}$ Similarly, the nutrition intervention was delivered over two sessions. In this intervention, women were provided with information about basic food groups, healthy food preparation, and how to develop a menu while shopping with little money. Both of these interventions were delivered by peer educators in group formats. In addition, both of these interventions aimed to engage women in a group setting to make changes to their health behaviors through providing social support within a new social context. Notably, significantly greater improvements in women's substance use abstinence occurred in both group-delivered intervention arms of the trial (the Women's Health $\mathrm{CoOp}$ and the nutrition groups) compared to the control arm, however improvements were greatest for the Women's Health CoOp group. ${ }^{33}$ Following these interventions, participants completed a series of follow-up appointments. After completion of their 12-month follow up appointment, women were eligible to participate in the indepth interviews to explore their responses to the program. Women selected for this portion of the study were stratified across diverse demographic characteristics (eg, ethnicity, age, HIV status, and children) and intervention arms (intervention, comparison, and control group participants). The goal of the study was to get ten women from each trial arm. Trained facilitators who had some interaction with the study participants during their appointments, assisted with identifying women who met the above criteria and who they felt would be vocal, comfortable and willing to share their experiences, as well as those who had experienced significant challenges (eg, partner violence or significant drug use) that would be relevant to the study outcomes.

\section{Participants}

Case study interviews were conducted with 30 women; a brief survey was also used to collect demographic information to ensure that the final sample was well-stratified across demographic characteristics. Forty percent $(n=12)$ of women were Black African and 60\% $(n=18)$ identified as Coloured (people of mixed race ancestry that self-identify as members of a particular cultural group). The majority (57\%) were 25 years of age or older. A small proportion of women (13\%) reported not having a relationship partner. Regarding the intervention group, we were able to recruit six women from the nutrition group, eight from HCT, and 16 from the Women's CoOp.

\section{Procedures}

Interviews used a semi-structured, open-ended narrative interview strategy to encourage free-flowing stories related to women's experiences in the program and changes in substance use, social relationships, and violence. Female facilitators, trained in interviewing and with experience working with these communities, conducted the interviews. The semi-structured interview probed for information on the barriers or successes related to reducing drug use, violence and power issues with male partners, other characteristics of relationships with primary male partners and sexual relationship partners, peer and family relationships, women's daily lives and any changes in their lives as a result of the program, and women's perspectives of the program (eg, what was most helpful and what could be improved). Immediately prior to the start of each interview, interviewers informed participants of the objectives and format of the interview, 
provided assurance of anonymity and obtained verbal consent for participation. Interviews were approximately 90 minutes long and were audiotaped and transcribed and transcripts were reviewed for accuracy against the recording. Some transcripts were translated if the interviews were not conducted in English. After completion of the interview, participants were provided a listing of local health, substance use, and violence-related services. Participants also received a ZAR80 gift card and a health kit to the value of ZAR100 (altogether, approximately $\$ 24$ at the time of the study) as compensation for their time. The protocol for this study was approved by the Human Subjects Committee at RTI International and Stellenbosch University's Health Research Ethics Committee.

\section{Data analyses}

The qualitative data from the interviews were analyzed using ATLAS-ti 6 (ATLAS-ti, Berlin, Germany). A content analysis approach ${ }^{37}$ was used to analyze the transcripts. Content analysis involves generating and applying codes to sections of text, then reviewing the text by various codes and "code families" to identify recurring themes. The coding team created an initial list of codes based on key domains and used these to code discussions. To enhance coding agreement, data were individually coded by two researchers, and coding procedures and definitions were discussed and compared for agreement. Additions of new codes or changes in code definitions were determined via consensus among the research team. No new codes emerged after two-thirds of the interviews were coded, suggesting that content saturation was achieved. Coded text was retrieved regarding programmatic and external factors that contributed to women's substance use reduction and abstinence as well as reductions in exposure to violence. The coding scheme was created to specifically retrieve scenarios where women reported social contexts or connections and social action as relevant to these outcomes.

\section{Results}

Social support (eg, via program staff and other participants) and social action (eg, engaging others in the community on issues relevant to substance use prevention or other health topics) promoted within the program, as well as outside social influences within women's life contexts (eg, support from non-substance using family or male partners, leaving male partners or other peer relationships characterized by drug use, or finding employment) were key factors reported by women in terms of facilitating their substance use abstinence and in reducing women's exposures to victimization. While social action was not promoted by the program curriculum explicitly, the group setting appeared to foster a sense of collectivity among women, and women identified a need, more broadly within the larger community, for women to support each other as well. Women also discussed a desire to educate and promote awareness regarding the information they learned as a result of participating in the program. The following are examples of these themes through the words of respondents.

\section{Program-specific effects reported by women: social contexts and social action in relation to women's drug abstinence and reduction of victimization}

Women from both the intervention (The Women's Health $\mathrm{CoOp}$ ) and nutrition (comparison) group reported decreased drug use, implying that the group dynamic (the component that was similar across the intervention and comparison groups), which included offering support and promoting women to support each other and others within their community, may have played a significant role in the observed reductions of drug use among women in these groups.

I really don't want to go back to the same cycle again because it was maddening. Waking every morning, even going to sleep at night you think about the next morning, where you're going to get a R40 to score. I mean it's at night but you're thinking about the next day. I don't want to go through that and the things that I used to do while I was on drugs. Because I wasn't working and my family were tired of giving me money, I had to prostitute. [Women's Health CoOp participant]

I stopped smoking [methamphetamine] ... . you have to love yourself and, I stopped because ... I did see it's going to get me nowhere. I'm going to end up dead or in jail. [Women's Health CoOp participant]

I just decided. I made a decision that this is not good for me. I can't live like this, you know, doing drugs. What do I gain? I gain nothing, it was destroying my life. ... I just quit. I told myself this is it. ... I just decided no, this is it for me. I've had enough [unclear]. I said one morning this is enough. [Nutrition program participant]

The drugs I was using, I do not use it so much anymore. ... I stopped. I felt like someone that would never be able to leave the drugs and when I became part of the study, then things started changing for me. That was a big [success] for me as it was difficult ... to get off the drugs ... [Women's Health CoOp participant] 
Women in the group-delivered interventions often noted an environment of social support within the program as relevant to their successes in abstinence or reductions in drug use.

I'd say they [staff] made me decide actually, they made me choose because at the end of the day, ... I have ... no reason for using these drugs .... I think it's good. I think it's very great fun, the ladies [staff]. Because, for me, it did work. ... Now I'm not using any drugs. I was using tik [methamphetamine], mandrax and buttons [methaqualone]. I was using even alcohol. I was using all the drugs that we get, the things that would get me high I used. [Women's Health CoOp participant]

When I came here it made me feel that I was not in this alone and it made me feel better and it made me feel more comfortable. [Women's Health CoOp participant]

Most of my friends are ... in the group. Girls who are ... trying to empower themselves ... . [participant is talking about staying friends with girls in the group from the program]. [Nutrition program participant]

Since I start here [the program] and the experience I ... learn here and they [staff] always ... telling me and ask me lot questions and so, so that made me go thinking and say for myself that I can stop [using drugs] ... I can stop ... [Women's Health CoOp participant]

Women in these group interventions also commonly reported a belief that social action and mobilization (learned through the program) would help other girls and women, and also noted an interest in continuing this social action.

I'm down for, for friends, sisterly gatherings and things like that and try to encourage each other. So being around women ... that actually like each other and doesn't fight with each other just because about this man and that man. ... they would help with each other's children in future and yeah and you could trust them more ... [Nutrition program participant]

Yeah and one of the main things hmm, when we done here right? All the clients [participants of the program], we should be able to go out and help the other girls at home [using the information we have learned in this program]. [Nutrition program participant]

In terms of women's perspectives of what is most needed in drug treatment interventions, women often discussed the drawbacks to substance abuse treatment centers. Women reported that these inpatient centers remove them completely from social interactions; both the positive and the negative influences of such networks. Women also perceived that these centers do not prepare them for returning to their usual social environment; whereas, women believed that if they quit on their own within their social environment, they would be more successful in recovery. Notably, women also mentioned that substance abuse treatment centers prevent women from pursuing employment or job training. Thus, for these reasons, few women reported using rehabs.

So I couldn't really take it because I wanted to be in the outside life, trying to get my life easy, you know. Like getting a job or finding some education. You can't really get those things on the inside so that's why I had to kind of stop on my own so that I could, you know. About rehab, I know that they keep you there. So I've never done rehab life and I didn't see a reason why I should be going back, like going to stay there full time as if I'm trying to get a way, whereas I believe I can get away even if I'm on the outside. [Women's Health CoOp participant]

[Quote from a woman suggesting future strategies for rehabilitation centers] Maybe if you could ... go to rehabs and maybe at the rehab centre they will be able to give you some education, doing your schooling at the rehab centre because you're out of that drug world, so why not use the chances. At the same time while you're there they're busy giving you education. You know that when you go out you're going to start living your life as a normal person, you'll be working [and thus, you will be in a different social environment]. [Women's Health CoOp participant]

She did not go because she wanted to learn on her own how to deal with problems. Because when you go to a rehab centre, people speak to you ... she wanted to learn to deal with the problems on her own [at home] because one day when that person is not there or when that person is not available, what are you going to do. You have to realise that you ... have to deal with your own problems [outside of the rehabilitation center]. [HCT participant]

Women reported that as a result of their participation in the program (both women in the Women's Health Co-Op intervention and the nutrition intervention), they experienced less victimization often as a result of leaving abusive relationships and decreasing the escalation of fights.

... he would force himself on me if I don't want to sleep with him ... [As a result of the program], I've changed but the world hasn't changed and I see people being in relationships that are not good for them. I know more and I will never let someone force themselves on me and not do anything about it now and I will never let anyone talk me into doing 
something that I don't want to do. I will speak up. Unlike that time I was afraid that I will never get my fix so I must obey whatever he tells me but now I will never let anyone do that to me. [Women's Health CoOp participant]

[The program] taught me if somebody is angry with me, if he ... is shouting at me I must just be cool or I must just go. [Women's Health CoOp participant]

I am a more humble person now [after the program]. ... I just walk away [to prevent a physical fight]. [Nutrition program participant]

Maybe the guy says something wrong or gives you a [clap sound, indicating being hit] also then I tend to do things that I can't control myself, but it's not the same now, it doesn't have the same effect. So yeah I don't get emotionally unstable anymore [after the program]. [Nutrition program participant]

\section{Women's social contexts outside the program and influence on drug abstinence}

Women often reported family and other social connections as a primary reason for stopping drug use.

It [referring to having her son] made me want to change. It made me want to get a job, try to do something good for my son because he's growing, you know. [HCT participant]

... there was a lot, like in my community, most people, a lot of people loves me a lot. So I was like no good for them when I smoked ... . [Women's Health CoOp participant]

... I could ... see the respect from people in my family, I just told myself, no, I don't think my life is even worth one hit, or a small hit. [Women's Health CoOp participant]

In order to reduce or stay abstinent from drugs, women often reported the need to end social connections that were promoting drug use and increasing social connections that were encouraging abstinence from substance use. For example, women reported challenges in leaving friends who use drugs.

I think it's the people, it's the friends. Because even with me I had to lose some of my friends because I decided I was stopping drugs. So if you have got no family to be there to support you, you always run to those friends and when you get to those friends the only things they give you is the drugs. So if you don't want to be using the drugs then how come you're following them in the first place? ... So you can never really stop because our friends are still using and we also want friends. Nobody wants to be alone at the end of the day. [Women's Health CoOp participant]
I didn't go out with my friends that I usually go with. ... And then I didn't take drugs anymore. [Women's Health CoOp participant]

They [friends who used drugs] took me like a stupid person, like I'm a nobody and insulting me like how is going to be your life, you're not going to be cool anymore so why are you stopping? Just keep on doing it just because it's the only way to be in this area. I was like no, no, that's not cool for me. ... they criticized me a lot. [Nutrition program participant]

... sometimes when I meet with my friends, we do smoke and then after that it's over. Then maybe I'm meeting them again after some time but they're not always around because I myself am not always around. When I'm around them that happens but when I'm not with them I'm free [of drugs]. [Women's Health CoOp participant]

Women also reported how important it was for them, in terms of their drug abstinence, to find positive social interaction and support for abstinence outside of their network of drug-using friends.

I left because I thought I need a push ... so I went to stay with my auntie even though she was also poor, but I think it's the best way ... Sometimes you stay in an [unhealthy] environment ... so you have to go ... When I came back, it was very hard because my friends mostly, they were drug [users] and when I had to come back it was hard ... [Women's Health CoOp participant]

My cousins was coming to visit my mother and I told them, can I please go stay even for two weeks, please, just to stay by your house. When she asked me why, I said because I don't want to smoke. ... it's not easy, hey, just to say that. [Women's Health CoOp participant]

Often women reported a need to leave boyfriends if they were also using drugs in order for women to stop their own drug use.

... he moved to Eastern Cape and I never really loved him

... he was someone who was there and he got jealous when I told him ... that I need more space but in the meantime after I came back from rehab he couldn't understand that and then he lost his job through drugging but I was away then. So he moved back to Eastern Cape ... . And he started giving me nasty calls and nasty messages so at the moment I' $m$ in the process of getting a court interdict for him. [Women's Health CoOp participant]

And then one day I just talked to my boyfriend, I really don't want to smoke but you people think smoke is my god. 
I really don't [want to smoke]. ... He's [the boyfriend] is not here now also, he's in prison now. [she left him to stay with her family for a while to get away from him and to try to quit smoking methamphetamine]. [Women's Health CoOp participant]

However, on the contrary, if women reported having male partners who did not use drugs, this was often reported as having a protective effect on their drug-use abstinence.

He was happy about it because I'm going to get some help [from being a participant in the program], then I'm going to stop using drugs. Because he was always telling me you must stop using drugs. So I didn't listen to him. And he was happy that maybe I will listen to somebody else. [Women's Health CoOp participant]

... we are planning a brighter future. He's planning to take me back to school and do some courses, like call centre stuff. Just because I dropped out from school because of these drugs I was smoking and now he wants me to go further in life, you know, to be someone. So that's what I like about him ... so he's a very good influence in my life. [Nutrition program participant]

He [boyfriend] really wants us to stop [using drugs]. At this point he really wants us both to stop using drugs, for real. And we are really trying, we're working on that because we have four children at stake and he wants us to be a happy family, drug-free, and to get the children what they want in life. [Women's Health CoOp participant]

In my relationship, because he does not do the things I do, my partner, he doesn't drink or smoke, and I felt like it's no use for me doing those things. [HCT participant]

In terms of seeking positive and alternative social networks, women often reported that employment was a way to change social environments and stay drug-free.

[Working] will keep me busy from bad things. Keep me busy; keep me away from the bad things. [Women's Health CoOp participant]

For some hours you'll be out of the township, out of the location, you come back late and then you're in [being away working would help in preventing relapse]. [Women's Health CoOp participant]

... it doesn't mean that ... if you work you gonna get a salary then ... use our salary for drugs. Working would actually keep you busy; you don't do it [use drugs] whole day or whatever the case may be it gets you away from it. ... Projects [like this one] keeping you busy ... these development courses help [reduce drug use]. [Nutrition program participant]

Women also reported that they wanted to seek employment as this would help them stay off drugs and also be able to financially support their families.

Women were asked what if anything would they like to change about their life; many mentioned that their children served as a motivator for behavior change.

To stop smoking, to get a better job and ... to raise my kid, yeah. I don't want to be rich 'no' ... I want to afford.

[Women's Health CoOp participant]

It [the program] made me want to change. It made me want to get a job, try to do something good for my son because he's growing, you know. ... I want to further my studies so I'm just looking for a way. [Women's Health CoOp participant]

Finding work ... so I can give my child what he needs ... Just by finding a work that will make it, that will make, that will change me more [staying off drugs]. I dream about getting a job so that my child and I can have a good life. [Women's Health CoOp participant]

\section{Discussion}

Findings from this study suggest that social support and the social action promoted within the group-delivered interventions, as well as social interactions that occurred outside of the context of these interventions, appear to be important factors influencing women's abstinence from substance use and reduced exposure to victimization. These findings are consistent with our previous published work, using quantitative survey data, which found that the Women's Health CoOp in particular, as well as the nutrition intervention groups, had significantly greater reductions in biologically verified substance use at 12 months follow-up, compared to those in the HCT control arm of the study. ${ }^{33}$ Findings from the current manuscript expand on this work by providing a broader understanding of the critical factors pertinent to women's social context that appear to be important mechanisms in women's substance use abstinence and reductions in victimization. To the best of our knowledge, this study is among the first to suggest that group-related social support that also promoted women to engage in social action outside the program (ie, community mobilization) appeared to foster reductions in substance use among women at risk for HIV within the South African context. However, current findings are consistent with previous work documenting the effectiveness of group-delivered interventions incorporating 
community mobilization strategies to reduce women's reports of gender-based violence, ${ }^{24-30}$ including previous work in South Africa. ${ }^{28-30}$ Findings have significant implications regarding the potential impact of future group-delivered interventions that explicitly include community mobilization strategies in terms of addressing women's substance use and related HIV risk.

Findings of the current study highlight the role that social environment plays in hindering or enhancing changes to substance use-related risk behaviors. Specifically, some women from this study highlighted the deleterious influence that neighborhood and peer networks characterized by substance use had on their efforts to quit substance use. They reported a need to leave substance-using social contexts through ending relationships with substance-using social networks and sometimes through physically leaving the geographic region where these relationships occurred in order to achieve abstinence from substances. While this is not surprising given the large body of literature which outlines the influence that neighborhood drug markets and social networks characterized by substance use have on the initiation and maintenance of substance use, ${ }^{38-42}$ to the best of our knowledge, this is the first South African study to highlight the role of environmental context and social networks in substance use maintenance.

Findings also highlight the role that substance-free social networks play in supporting abstinence from substance use and reduced victimization. Several participants in this study reported that they had to build positive social interactions and substance-free support systems to support their abstinence from substance use abstinence and replace their substance-using networks. This finding builds on previous work documenting the important influence of social drivers in facilitating abstinence from substance use. ${ }^{13,40,43-46}$

In keeping with previous work on the topic, ${ }^{13,43,46,47}$ our findings highlight the positive impact that the support of family and friends who do not use substances can have on some women's efforts to quit substances. Several participants seemed to find the group sessions useful in this regard, reporting that these group interventions offered them a new and positive social environment within which to seek support, facilitated the development of positive social networks, created capacity for leaving social contexts and relationships where substance use and victimization was promoted, and helped them feel empowered to take action to promote social change within their communities. Together, these factors appeared to reinforce abstinence from substance use and reduce victimization among women who participated in these group interventions. Our finding that the women-focused group intervention appeared to offer women new positive social connections that help promote abstinence from substance use strengthens the small body of literature on this topic, ${ }^{40}$ and expands upon this earlier work by highlighting the potential role that community mobilization and social action may play in reinforcing women's substance use abstinence.

Importantly, participants in this study (regardless of intervention arm) did not view substance abuse treatment centers as helpful in facilitating the establishment of substance-free social networks and social environments. Earlier studies of substance abuse treatment in South Africa have noted that women from disadvantaged communities often have very negative perceptions of substance abuse treatment that hinder their use of these facilities; with these perceptions centered around treatment facilities not being effective and not responding to their service needs ${ }^{48}$ and that women experience more barriers (childcare or partner violence) to accessing substance abuse treatment than men. ${ }^{49}$ This study builds on this earlier work by demonstrating that some women do not view substance abuse treatment facilities as helpful for creating substance-free social networks that can help maintain abstinence from drug use after completion of treatment. Related to this, several participants also did not view these centers as helpful in preparing women for drugfree lives through vocational training or further education. These findings are important as they highlight areas in which South African substance abuse treatment facilities can improve their responsiveness to the service needs of women. In fact, many participants in our study noted that job training and support should be included as a strategy to help reinforce drug use abstinence as this would allow women access to new social networks, exposure to alternative and healthy social and physical environments, and help them provide for their children, thereby helping them achieve a sense of fulfillment. Current study findings suggest that more work is needed to evaluate and better understand how best to incorporate social collectiveness, support-building, and social action components, including education and job training, into current substance abuse treatment programs.

The present findings should be considered in light of several limitations. First, women who were vocal and who were perceived as participants who would provide more information were often selected for interviews; and while equal stratification across trial arm was intended, we were not able to recruit an equal sample across arms. Thus, these recruitment factors may have limited the variability of our 
sample and consequently the extent to which these findings are generalizable to all participants of the larger study. Furthermore, the participants in this study were from disadvantaged urban "township" communities, where substance use, HIV, and poverty intersect, and thus, findings may not be generalizable to other contexts. While this qualitative study of women suggests that social connections (as participants in a group intervention, and outside of the program) were key to women's reductions in substance use and exposure to victimization, future quantitative research that uses a rigorous study design and directly examines the impact of social support-building and social action on substance use and victimization is needed to confirm and expand on these findings. Finally, stigmatized behaviors, such as women's self-reported responses regarding their substance use and victimization, may be under-reported. However, in this study interviewers used techniques that normalized the reporting of socially undesirable behaviors and perceived that respondents spoke freely about their behaviors. Furthermore, interview findings related to increased substance use abstinence are consistent with our previous published work documenting significant reductions in biologically-verified substance use among women in group-directed intervention trial arms compared to the control group.

These limitations notwithstanding, the present study builds on previous work highlighting the influence of women-focused group interventions as well as women's social connections in reducing substance use and victimization..$^{13,14}$ The current study further expands on such work by highlighting the potential for social action and mobilization for facilitating and maintaining abstinence from drug use and reduced victimization. Findings related to the impact of group-delivered interventions also have particular implications for future work in resource-scarce settings; group interventions are potentially more feasible to implement and sustainable long-term compared to resourceintensive, individually-delivered interventions. Programs similar to these may have an impact in other regions where there are little to no treatment facilities and peer interventions may be able to mobilize and support positive social action within resource-poor communities where women can find support from each other.

\section{Acknowledgments}

This research was supported by grant R01HD058320 from the Eunice Kennedy Shriver National Institute of Child Health and Human Development (NICHD), National Institutes of Health, United States Department of Health and Human Services (HHS). The interpretations and conclusions presented here are those of the authors and do not necessarily represent the position of NICHD or HHS. We wish to thank Sindhu Ravishankar and Ashley Sorgi for the initial coding.

\section{Disclosure}

The authors report no conflicts of interest in this work.

\section{References}

1. Bradshaw D, Nannan N, Laubscher R, et al. South African National Burden of Disease Study: Estimates of Provincial Mortality. Cape Town: South African Medical Research Council; 2006. Available from: http:// www.mrc.ac.za/bod/estimate.pdf. Accessed May 31, 2013.

2. National Department of Health. Report on National HIV and Syphilis Antenatal Sero-Prevalence Survey in South Africa. Pretoria: National Department of Health; 2011.

3. Abdool Karim SS, Churchyard GJ, Karim QA, Lawn SD. HIV infection and tuberculosis in South Africa: an urgent need to escalate the public health response. Lancet. 2009;374(9693):921-933.

4. Jewkes R, Morrell R. Gender and sexuality: emerging perspectives from the heterosexual epidemic in South Africa and implications for HIV risk and prevention. J Int AIDS Soc. 2010;13:6.

5. Luseno WK, Wechsberg WM, Kline TL, Ellerson RM. Health services utilization among South African women living with HIV and reporting sexual and substance-use risk behaviors. AIDS Patient Care STDS. 2010;24(4):257-264.

6. Browne FA, Wechsberg WM. The intersecting risks of substance use and HIV risk among substance-using South African men and women. Curr Opin Psychiatry. 2010;23(3):205-209.

7. Luseno WK, Wechsberg WM. Correlates of HIV testing among South African women with high sexual and substance-use risk behaviours. AIDS Care. 2009;21(2):178-184.

8. Wechsberg WM, Luseno W, Riehman K, Karg R, Browne F, Parry C. Substance use and sexual risk within the context of gender inequality in South Africa. Subst Use Misuse. 2008;43(8-9):1186-1201.

9. Gilbert L, El-Bassel N, Manuel J, et al. An integrated relapse prevention and relationship safety intervention for women on methadone: testing short-term effects on intimate partner violence and substance use. Violence Vict. 2006;21(5):657-672.

10. Herman AA, Stein DJ, Seedat S, Heeringa SG, Moomal H, Williams DR. The South African Stress and Health (SASH) study: 12-month and lifetime prevalence of common mental disorders. S Afr Med J. 2009; 99(5 Pt 2):339-344.

11. Pasche S, Myers B. Substance misuse trends in South Africa. Hum Psychopharmacol. 2012;27(3):338-341.

12. Peltzer K, Davids A, Njuho P. Alcohol use and problem drinking in South Africa: findings from a national population-based survey. Afr $J$ Psychiatry (Johannesbg). 2011;14(1):30-37.

13. El-Bassel N, Wechsberg WM, Shaw SA. Dual HIV risk and vulnerabilities among women who use or inject drugs: no single prevention strategy is the answer. Curr Opin HIV AIDS. 2012;7(4):326-331.

14. Wechsberg WM, Luseno WK, Lam WK, Parry CD, Morojele NK. Substance use, sexual risk, and violence: HIV prevention intervention with sex workers in Pretoria. AIDS Behav. 2006;10(2):131-137.

15. Wechsberg WM, Myers B, Kline TL, Carney T, Browne FA, Novak SP. The relationship of alcohol and other drug use typologies to sex risk behaviors among vulnerable women in Cape Town, South Africa. J AIDS Clin Res. 2012;S1(15).

16. Dunkle KL, Jewkes RK, Brown HC, Gray GE, McIntryre JA, Harlow SD. Transactional sex among women in Soweto, South Africa: prevalence, risk factors and association with HIV infection. Soc Sci Med. 2004;59(8):1581-1592.

17. Jewkes R, Levin J, Penn-Kekana L. Risk factors for domestic violence: findings from a South African cross-sectional study. Soc Sci Med. 2002;55(9):1603-1617. 
18. Jewkes R, Dunkle K, Nduna M, et al. Factors associated with HIV sero-positivity in young, rural South African men. Int J Epidemiol. 2006;35(6):1455-1460.

19. Jewkes RK, Dunkle K, Nduna M, Shai N. Intimate partner violence, relationship power inequity, and incidence of HIV infection in young women in South Africa: a cohort study. Lancet. 2010;376(9734):41-48.

20. Jewkes R, Abrahams N. The epidemiology of rape and sexual coercion in South Africa: an overview. Soc Sci Med. 2002;55(7):1231-1244.

21. Dunkle KL, Jewkes RK, Nduna M, et al. Perpetration of partner violence and HIV risk behaviour among young men in the rural Eastern Cape, South Africa. AIDS. 2006;20(16):2107-2114.

22. Decker MR, Seage GR, Hemenway D, et al. Intimate partner violence functions as both a risk marker and risk factor for women's HIV infection: findings from Indian husband-wife dyads. J Acquir Immune Defic Syndr. 2009;51(5):593-600.

23. Jewkes R, Sikweyiya Y, Morrell R, Dunkle K. The relationship between intimate partner violence, rape and HIV amongst South African men: a cross-sectional study. PLoS ONE. 2011;6(9):e24256.

24. Blankenship KM, West BS, Kershaw TS, Biradavolu MR. Power, community mobilization, and condom use practices among female sex workers in Andhra Pradesh, India. AIDS. 2008;22 Suppl 5:S109-S116.

25. Parimi P, Mishra RM, Tucker S, Saggurti N. Mobilising community collectivisation among female sex workers to promote STI service utilisation from the government healthcare system in Andhra Pradesh, India. J Epidemiol Community Health. 2012;66 Suppl 2:ii62-ii68.

26. Shahmanesh M, Patel V, Mabey D, Cowan F. Effectiveness of interventions for the prevention of HIV and other sexually transmitted infections in female sex workers in resource poor setting: a systematic review. Trop Med Int Health. 2008;13(5):659-679.

27. Jana S, Basu I, Rotheram-Borus MJ, Newman PA. The Sonagachi Project: a sustainable community intervention program. AIDS Educ Prev. 2004;16(5):405-414.

28. Kim J, Ferrari G, Abramsky T, et al. Assessing the incremental effects of combining economic and health interventions: the IMAGE study in South Africa. Bull World Health Organ. 2009;87(11):824-832.

29. Kim JC, Watts CH, Hargreaves JR, et al. Understanding the impact of a microfinance-based intervention on women's empowerment and the reduction of intimate partner violence in South Africa. Am J Public Health. 2007;97(10):1794-1802.

30. Pronyk PM, Hargreaves JR, Kim JC, et al. Effect of a structural intervention for the prevention of intimate-partner violence and HIV in rural South Africa: a cluster randomised trial. Lancet. 2006;368(9551): 1973-1983.

31. Dürsteler-MacFarland KM, Farronato NS, Strasser J, et al. A randomized, controlled, pilot trial of methylphenidate and cognitive-behavioral group therapy for cocaine dependence in heroin prescription. $J$ Clin Psychopharmacol. 2013;33(1):104-108.

32. Ashton K, Heinberg L, Merrell J, Lavery M, Windover A, Alcorn K. Pilot evaluation of a substance abuse prevention group intervention for at-risk bariatric surgery candidates. Surg Obes Relat Dis. 2013.

33. Wechsberg WM, Jewkes R, Novak S, et al. A brief intervention for drug use, sexual risk behaviours and violence prevention with vulnerable women in South Africa: Randomised controlled trial of the Women's Health CoOp. BMJ Open. 2013;3:e002622.
34. Jones HE, Browne FA, Myers BJ, et al. Pregnant and nonpregnant women in cape town, South Africa: drug use, sexual behavior, and the need for comprehensive services. Int J Pediatr. 2011;2011:353410.

35. Johnson JE, Carney T, Kline T, Browne FA, Wechsberg WM. Incarceration history relative to health, substance use, and violence in a sample of vulnerable South African women: implications for health services in criminal justice settings. Subst Abuse Rehabil.2012;3(Suppl 1):59-69.

36. Wechsberg WM, Luseno WK, Karg RS, et al. Alcohol, cannabis, and methamphetamine use and other risk behaviours among Black and Coloured South African women: a small randomized trial in the Western Cape. Int J Drug Policy. 2008;19(2):130-139.

37. Ryan G, Weisner T. Analyzing words in brief descriptions: fathers and mothers describe their children. Field Methods. 1996;8(3):13-16.

38. Buchanan AS, Latkin CA. Drug use in the social networks of heroin and cocaine users before and after drug cessation. Drug Alcohol Depend. 2008;96(3):286-289.

39. Schroeder JR, Latkin CA, Hoover DR, Curry AD, Knowlton AR, Celentano DD. Illicit drug use in one's social network and in one's neighborhood predicts individual heroin and cocaine use. Ann Epidemiol. 2001;11(6):389-394.

40. Miller M, Neaigus A. Networks, resources and risk among women who use drugs. Soc Sci Med. 2001;52(6):967-978.

41. Friedman SR, Neaigus A, Jose B, et al. Sociometric risk networks and risk for HIV infection. Am J Public Health. 1997;87(8):1289-1296.

42. Rhodes T, Quirk A. Drug users' sexual relationships and the social organisation of risk: the sexual relationship as a site of risk management. Soc Sci Med. 1998;46(2):157-169.

43. El-Bassel N, Gilbert L, Witte S, Wu E, Chang M. Intimate partner violence and HIV among drug-involved women: contexts linking these two epidemics - challenges and implications for prevention and treatment. Subst Use Misuse. 2011;46(2-3):295-306.

44. el-Bassel N, Schilling RF. Social support and sexual risk taking among women on methadone. AIDS Educ Prev. 1994;6(6):506-513.

45. Panchanadeswaran S, El-Bassel N, Gilbert L, Wu E, Chang M. An examination of the perceived social support levels of women in methadone maintenance treatment programs who experience various forms of intimate partner violence. Womens Health Issues. 2008;18(1):35-43.

46. von Diemen L, De Boni R, Kessler F, Benzano D, Pechansky F. Risk behaviors for HCV- and HIV-seroprevalence among female crack users in Porto Alegre, Brazil. Arch Womens Ment Health. 2010;13(3): 185-191.

47. Wechsberg WM, Parry CDH, Jewkes RK. Drugs, Sex, Gender-Based Violence, and the Intersection of the HIV/AIDS Epidemic with Vulnerable Women in South Africa. Research Triangle Park: RTI Press; 2010.

48. Myers B, Fakier N, Louw J. Stigma, treatment beliefs, and substance abuse treatment use in historically disadvantaged communities. Afr $J$ Psychiatry (Johannesbg). 2009;12(3):218-222.

49. Myers B, Louw J, Pasche S. Gender differences in barriers to alcohol and other drug treatment in Cape Town, South Africa. Afr J Psychiatry (Johannesbg). 2011;14(2):146-153
Substance Abuse and Rehabilitation

\section{Publish your work in this journal}

Substance Abuse and Rehabilitation is an international, peer-reviewed, open access journal publishing original research, case reports, editorials, reviews and commentaries on all areas of addiction and substance abuse and options for treatment and rehabilitation. The manuscript management system is completely online and includes a very quick and fair
Dovepress

peer-review system. Visit http://www.dovepress.com/testimonials.php to read real quotes from published authors. 